\title{
Sib-pair Analysis Detects Elevated Lp(a) Levels and Large Variation of Lp(a) Concentration in Subjects with Familial Defective ApoB
}

Ytje Y. van der Hoek, ${ }^{\star \ddagger}$ Arno Lingenhel, ${ }^{\S}$ Hans G. Kraft, ${ }^{\S}$ Joep C. Defesche, ${ }^{\star}$ John J.P. Kastelein, ${ }^{\star}$ and Gerd Utermann ${ }^{\S}$ *Department of Vascular Medicine, Academical Medical Centre, University of Amsterdam, 1105 AZ Amsterdam, The Netherlands; ${ }^{\ddagger}$ Department of Clinical Chemistry, St. Antonius Hospital, 3435 CM Nieuwegein, The Netherlands; and ${ }^{\S}$ Institute for Medical Biology and Human Genetics, University of Innsbruck, 6020 Innsbruck, Austria

\begin{abstract}
Whether or not Lp(a) plasma levels are affected by the apoB R3500Q mutation, which causes Familial Defective apoB (FDB), is still a matter of debate. We have analyzed 300 family members of 13 unrelated Dutch index patients for the apoB mutation and the apolipoprotein(a) [apo(a)] genotype. Total cholesterol, LDL-cholesterol, and lipoprotein(a) [Lp(a)] concentrations were determined in 85 FDB heterozygotes and 106 non-FDB relatives. Mean LDL levels were significantly elevated in FDB subjects compared to nonFDB relatives $(P<0.001)$. Median $L p(a)$ levels were not different between FDB subjects and their non-FDB relatives. In contrast, sib-pair analysis demonstrated a significant effect of the FDB status on $\mathrm{Lp}(\mathrm{a})$ levels. In sib pairs identical by descent for apo(a) alleles but discordant for the FDB mutation $(n=11)$ each sib with FDB had a higher Lp(a) level than the corresponding non-FDB sib. Further, all possible sib pairs $(n=105)$ were grouped into three categories according to the absence/presence of the apoB R3500Q mutation in one or both subjects of a sib pair. The variability of differences in $\mathrm{Lp}(\mathrm{a})$ levels within the sib pairs increased with the number $(0,1$, and 2$)$ of FDB subjects present in the sib pair. This suggests that the FDB status increases $L p(a)$ level and variability, and that $\mathrm{apoB}$ may be a variability gene for Lp(a) levels in plasma. (J. Clin. Invest. 1997. 99: 2269-2273.) Key words: Familial Defective apoB • sib-pair analysis $\bullet$ lipoprotein(a) - apolipoprotein(a) • variability gene
\end{abstract}

\section{Introduction}

Lipoprotein(a) $[\mathrm{Lp}(\mathrm{a})]^{1}$ is a strong and independent risk factor for atherothrombotic disease (1). Humans vary widely in

Y.Y. van der Hoek and A. Lingenhel contributed equally to this manuscript.

Address correspondence to Dr. H.G. Kraft, Inst. F. Med. Biology and Human Genetics, Schoepfstr. 41, A-6020 Innsbruck, Austria. Phone: 43-512-507-3451; FAX: 43-512-507-2861; E-mail: hans-georg. kraft@uibk.ac.at

Received for publication 17 December 1996 and accepted in revised form 21 February 1997.

1. Abbreviations used in this paper: apo(a), apolipoprotein(a); FDB, Familial Defective apoB; FH, familial hypercholesterolemia; i.b.d., identical by descent; K-IV, Kringle IV; Lp(a), lipoprotein(a); PFGE, pulsed field gel electrophoresis.

J. Clin. Invest.

(C) The American Society for Clinical Investigation, Inc.

0021-9738/97/05/2269/05 \$2.00

Volume 99, Number 9, May 1997, 2269-2273 plasma $\mathrm{Lp}$ (a) concentrations (from $<1 \mathrm{mg} / \mathrm{dl}$ to $>300 \mathrm{mg} / \mathrm{dl}$ ), whereas risk-associated levels are in the range above $30 \mathrm{mg} / \mathrm{dl}$. Lp(a) levels are almost entirely genetically determined (2-4) and are relatively resistant to dietary and drug intervention (5-7). $\mathrm{Lp}(\mathrm{a})$ is similar to LDL in its composition consisting of cholesterol, phospholipids, and apolipoproteinB-100 (apoB100). The distinguishing feature of the $\mathrm{Lp}(\mathrm{a})$ particle is the presence of an additional glycoprotein designated apolipoprotein(a) [apo(a)], which is linked to apoB-100 by a disulfide bond (8-10). Analysis of the apo(a) cDNA revealed a remarkable homology with plasminogen which extends to functional properties, which might, in part, explain the thrombogenic properties of $\mathrm{Lp}(\mathrm{a})$ (11).

The presence of apoB-100 in the $\mathrm{Lp}(\mathrm{a})$ particle suggests that Lp(a) may interact with the LDL receptor. Several studies have investigated the possible role of the LDL receptor in the removal of $\mathrm{Lp}(\mathrm{a})$ from plasma, but they have resulted in conflicting data and interpretations. Still, it is not clear whether $\mathrm{Lp}(\mathrm{a})$ is bound and taken up by this receptor in humans in vivo (12-17).

Familial Defective apolipoproteinB-100 (FDB) is a genetic disorder caused by a substitution in the gene for apoB-100 that changes an arginine residue to a glutamine at position 3,500 in the mature protein (reviewed by Hansen and Humphries [18]). LDL particles containing apoB with this R3500Q substitution bind poorly to the LDL receptor in in vitro experiments. Subjects heterozygous for FDB typically exhibit an elevated plasma concentration of LDL, with a higher proportion $(\sim 70 \%)$ of LDL particles containing the defective apoB-100 (19). Studies involving subjects suffering from this disorder can provide information on the metabolism of $\mathrm{Lp}(\mathrm{a})$ by measuring and comparing $\mathrm{Lp}(\mathrm{a})$ levels in FDB patients and their non-FDB relatives. This requires exclusion of other confounding factors including the most important: the apo(a) Kringle IV (K-IV) repeat polymorphism. Therefore, we performed a sib-pair analysis in which both the FDB status and apo(a) K-IV repeat polymorphism were considered. This allowed us to address whether or not $\mathrm{Lp}(\mathrm{a})$ is affected by the FDB status.

\section{Methods}

Subjects. From 1989 through 1994, 5,000 patients were referred to the Lipid Research Clinic at the Slotervaart Hospital and the Academical Medical Centre of the University of Amsterdam for treatment of several disorders of lipoprotein metabolism. Initially, over 800 patients were diagnosed as suffering from Familial Hypercholesterolemia $(\mathrm{FH})(20)$. Screening this $\mathrm{FH}$ population for the presence of the apoB3500 substitution (see below) resulted in the identification of 13 unrelated patients carrying the apoB R3500Q substitution, and these subjects were identified as Familial Defective apolipoprotein B-100 (FDB) patients. With the assistance and consent of each FDB index patient, family meetings were arranged where pedigrees were constructed and blood was drawn. From each relative, $30 \mathrm{ml}$ of blood was collected by venipuncture in tubes containing EDTA. $5 \mathrm{ml}$ 
of blood was immediately frozen at $-20^{\circ} \mathrm{C}$ for preparation of large intact genomic DNA for pulsed field gel electrophoresis (PFGE), and the remainder was separated by centrifugation into plasma and cells. Plasma was used for lipid and lipoprotein analysis, and genomic DNA was isolated from the buffy coat as described previously (21). The study protocol was approved by the Institutional Review Board, and written informed consent was obtained from all participants.

Lipid and lipoprotein analysis. Total plasma cholesterol and triglycerides were measured after overnight fasting by an enzymatic method $(22,23)$. The HDL cholesterol was determined by measuring cholesterol in the supernatant after precipitation of the apoB containing lipoproteins [very low density lipoprotein (VLDL), LDL and $\mathrm{Lp}(\mathrm{a})$ ] as published previously (24). The LDL-cholesterol levels were then calculated from total plasma cholesterol, triglyceride, and HDLcholesterol levels by the Friedewald formula (25). Lp(a) plasma concentration was measured by an electroimmunodiffusion procedure (26) and by an ELISA (27).

Detection of apoB3500 mutation. The FDB family members were screened for the presence of the apoB R3500Q mutation by a mutagenic PCR technique with sequence modifying primers as described previously (20). Briefly, a 477-bp fragment of exon 26 of the apoB gene (nucleotide position 10,675-11,151) was amplified. This fragment also contained the naturally occurring restriction fragment length polymorphism of the restriction endonuclease MspI at nucleotide position 11,030. After PCR, $10 \mu \mathrm{l}$ of the reaction mixture was digested with MspI, using conditions recommended by the supplier (New England Biolabs Inc., Beverly, MA). Digestion products were separated on $2 \%$ agarose gels in TBE buffer ( $90 \mathrm{mM}$ Tris, $90 \mathrm{mM}$ borate, 2 mM EDTA, $\mathrm{pH}$ 8.0) and visualized by staining with ethidium bromide.

Apo(a) DNA phenotyping with PFGE. The number of K-IV repeats in the apo(a) alleles was determined by PFGE and Southern blotting of KpnI digested genomic DNA exactly as described previously (4). The preparation of DNA containing plugs was modified because frozen blood was used instead of fresh blood. The frozen EDTA blood was thawed and transferred to a 50-ml tube. The tube was filled with sterile, ice-cold lysis buffer $(20 \mathrm{mM}$ Tris- $\mathrm{HCl}, 10 \mathrm{mM}$ EDTA, $\mathrm{pH} \mathrm{8.0)}$ and centrifuged for $10 \mathrm{~min}$ at 4,000 rpm. The supernatant was discarded and the cell pellet was resuspended in $1 \mathrm{ml}$ of TE buffer (10 mM Tris, $1 \mathrm{mM}$ EDTA, $\mathrm{pH}$ 8.0). The cell suspension was mixed carefully with the same volume of $1.2 \%$ low melting point (LMP) agarose and poured into plug-forming molds. Plugs were solidified for $30 \mathrm{~min}$ at $4^{\circ} \mathrm{C}$ and then washed in $10 \mathrm{ml}$ of ES buffer $(0.5 \mathrm{M}$ EDTA, $\mathrm{pH}$ 8.0, $1 \%$ lauroylsarcosine) to remove hemoglobin. The following steps, treatment with proteinase $\mathrm{K}$, and the washing and storage of the plugs, were performed as described previously (4).

Table I. Mean Age, Total Cholesterol (TC), LDL-Cholesterol ( $L D L-C)$, and $L p(a)$ Levels in FDB and Non-FDB Relatives Divided by Gender

\begin{tabular}{lccl}
\hline & FDB & Non-FDB & \\
\hline Women & $n=47$ & $n=51$ & \\
Age (yr) & $48 \pm 17$ & $39 \pm 12$ & \\
TC (mmol/liter) & $8.2 \pm 1.0$ & $5.6 \pm 0.9$ & $P<0.0001$ \\
LDL-C (mmol/liter) & $6.1 \pm 1.1$ & $3.6 \pm 0.8$ & $P<0.0001$ \\
Lp(a) (mg/dl) & $23.4 \pm 23.0$ & $17.6 \pm 15.9$ & $P=0.56^{*}$ \\
Men & $n=38$ & $n=55$ & \\
Age (yr) & $43 \pm 15$ & $43 \pm 14$ & \\
TC (mmol/liter) & $7.1 \pm 1.2$ & $5.7 \pm 1.1$ & $P<0.0001$ \\
LDL-C (mmol/liter) & $5.4 \pm 1.3$ & $3.6 \pm 0.9$ & $P<0.0001$ \\
Lp(a) (mg/dl) & $17.3 \pm 17.5$ & $19.3 \pm 19.0$ & $P=0.48^{*}$ \\
& & &
\end{tabular}

*Wilcoxon two sample test.
Statistical methods. Total cholesterol and LDL-cholesterol between FDB and non-FDB subjects were compared by the paired $t$ test. $\mathrm{Lp}$ (a) concentrations were compared by the Wilcoxon two samples test. Sib-pair analysis was performed in two ways: (a) Lp(a) concentrations were compared between sibs who were identical by descent for apo(a) alleles but discordant for the apoB3500 mutation by the nonparametric Wilcoxon matched-pairs signed rank test; $(b)$ sib pairs were grouped according to the presence or absence of the FDB mutation into non-FDB/non-FDB, non-FDB/FDB, and FDB/FDB sib pairs. The squared difference $\left(\Delta^{2}\right)$ of the $L p(a)$ concentrations within each sib pair was then calculated and divided by the absolute difference in the number of K-IV repeats between the sib pairs. This was done to account for the influence of the size polymorphism on the $\Delta^{2}$ values.

The effect of the K-IV repeat polymorphism on the Lp(a) concentration was calculated by the $\mathrm{R}^{2}$ statistics of the analysis of variance, and by Spearman rank correlation taking the log transformed $\mathrm{Lp}$ (a) concentration as the dependent variable. All calculations were performed using the SPSS package (Windows version 6.1.2).

\section{Results}

Lipid and lipoprotein analysis. Plasma concentrations of total cholesterol, LDL-cholesterol, and Lp(a) were measured in available family members of 13 families in whom the inheritance of the R3500Q mutation in apoB-100 could be tracked. The results are shown in Table I. In both genders, total cholesterol and LDL-cholesterol levels were significantly increased in the subjects carrying the apoB R3500Q mutation $(P<$ 0.0001). Median Lp(a) levels (25th and 75th percentile), however, did not differ significantly between patients suffering from FDB $(9 ; 3 ; 30.5 \mathrm{mg} / \mathrm{dl})$ and their non-FDB relatives $(9 ; 3$; $22.75 \mathrm{mg} / \mathrm{dl})$.

Sib pair comparison. Apo(a) genotypes were determined in 13 FDB families corresponding to a total of $\sim 300$ family members. In the 13 families, 11 informative sib pairs were identified. Sibs were considered informative $(a)$ if both sibs had inherited identical apo(a) alleles from their parents (i.e., they were identical by descent [i.b.d.] for the apo(a) alleles), and $(b)$ if one sib was FDB affected and the other was not. Fig. 1 shows an example of a pedigree from an FDB family. Lp(a) plasma concentrations, apo(a) genotype, and the presence or absence of the FDB mutation are indicated. In this particular family, three of the seven siblings were heterozygous for FDB. Three out of the four possible apo(a) allele combinations were observed. The father was deceased but it could be deduced from the pedigree that he was heterozygous for the apoB3500 substitution and possessed apo(a) alleles 32/37. The bottom of Fig. 1 shows the Southern blot of PFGE separated KpnI fragments of genomic DNA from each sibling in the FDB family. In this family II:2 and II:3 both had FDB and shared both apo(a) alleles with II: 6 who did not carry the FDB mutation. FDB subject II:4 had identical apo(a) alleles as the non-FDB sibs II:5 and II:7.

Table II shows the Lp(a) level, apo(a) genotype defined by the number of K-IV repeats present in each of the two apo(a) alleles, age, and gender of all 11 sib pairs. In every sib pair the sibling with FDB had the higher Lp(a) concentration when compared to the sibling without FDB. This difference was highly significant (Wilcoxon matched-pairs signed rank test; $P=0.0033$ ). In the next step we grouped all possible sib pairs $(n=105)$ into three categories: $(a)$ sib pairs concordant for the absence of FDB $(n=20) ;(b)$ discordant for the presence of 

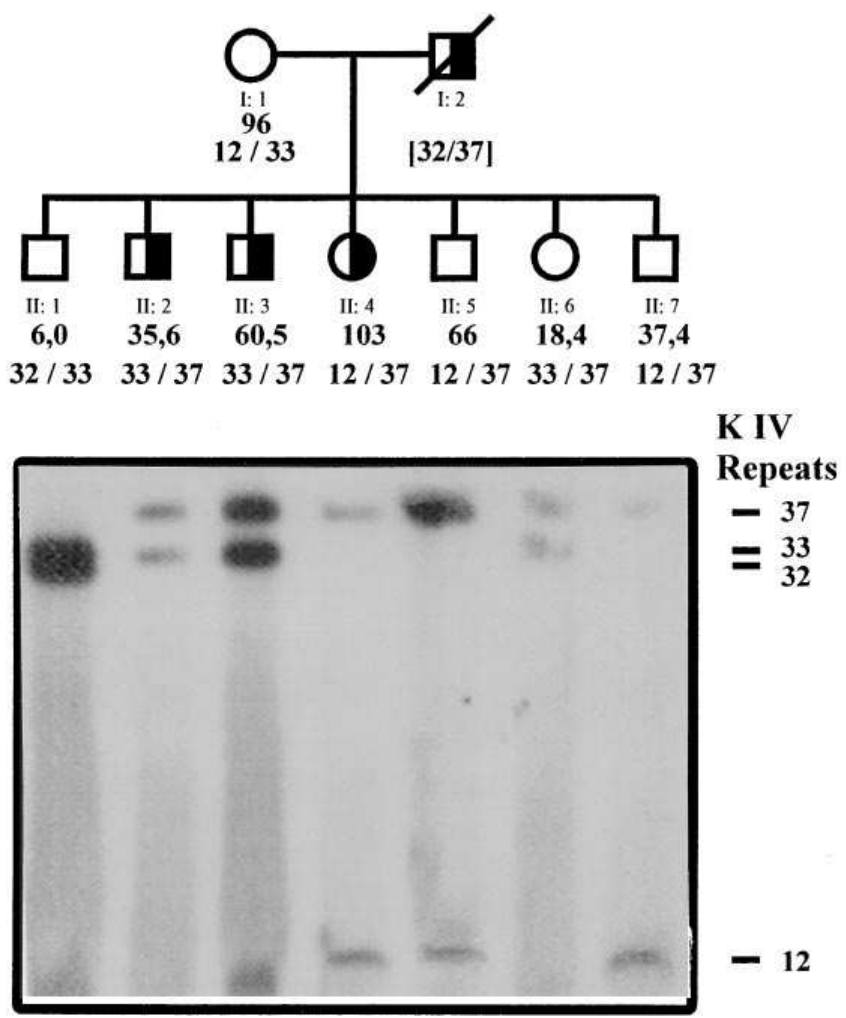

Figure 1. The top shows an informative pedigree of an FDB family. The Lp(a) concentrations (mg/dl) and the apo(a) DNA phenotype [expressed as numbers of K-IV repeats in the apo(a) alleles] are indicated below the family ID numbers. The deduced apo(a) DNA phenotype of the father is given in brackets. The bottom shows the corresponding chemiluminogram of a PFGE/Southern blot (see Methods) demonstrating the apo(a) phenotypes from the seven sibs of the family. The numbers of K-IV repeats in the apo(a) alleles are indicated on the right. Sibs II: 2, II: 3, and II: 6 are i.b.d. for apo(a) alleles 33/37 and sibs II: 4, II: 5, and II: 7 are i.b.d. for apo(a) alleles 12/37.

FDB $(n=59)$; and $(c)$ concordant for the presence of the apoB-100 mutation $(n=26)$. This was done to estimate whether the presence of the FDB mutation has an effect on the variation of $\operatorname{Lp}(\mathrm{a})$ concentration. We determined the dif-
Table II. Lp(a) Levels (mg/dl), Apo(a) DNA Phenotype, Age, and Gender in Sib Pairs Who Carry Apo(a) Alleles Identical by Descent but Are Discordant for the ApoB R3500Q Mutation

\begin{tabular}{ccccccc}
\hline & & \multicolumn{2}{c}{$\mathrm{Lp}(\mathrm{a}) \mathrm{mg} / \mathrm{dl}$} & & \multicolumn{2}{c}{ Age (sex) } \\
\cline { 7 - 7 } Sib pair & $\begin{array}{c}\text { Apo(a) alleles } \\
\text { No. of K-IV repeats }\end{array}$ & FDB & Non-FDB & & FDB & Non-FDB \\
\hline 1 & $27 / 38$ & 17 & $15^{*}$ & & $66(\mathrm{~F})$ & $45(\mathrm{~F})$ \\
2 & $27 / 38$ & 24 & $15^{*}$ & & $65(\mathrm{~F})$ & $45(\mathrm{~F})$ \\
3 & $33 / 38$ & 1.4 & 1.0 & & $35(\mathrm{M})$ & $37(\mathrm{~F})$ \\
4 & $33 / 37$ & 35.6 & $18.4^{*}$ & & $66(\mathrm{M})$ & $50(\mathrm{~F})$ \\
5 & $33 / 37$ & 60.5 & $18.4^{*}$ & & $64(\mathrm{M})$ & $50(\mathrm{~F})$ \\
6 & $12 / 37$ & $103^{*}$ & 66.0 & & $63(\mathrm{~F})$ & $56(\mathrm{M})$ \\
7 & $12 / 37$ & $103^{*}$ & 37.4 & & $63(\mathrm{~F})$ & $48(\mathrm{M})$ \\
8 & $28 / 34$ & 0.3 & 0.2 & & $21(\mathrm{~F})$ & $18(\mathrm{~F})$ \\
9 & $20 / 34$ & 64 & 39.5 & & $60(\mathrm{~F})$ & $66(\mathrm{~F})$ \\
10 & $33 / 38$ & 24.8 & 5.9 & & $61(\mathrm{M})$ & $69(\mathrm{M})$ \\
11 & $34 / 38$ & 8 & 7 & & $78(\mathrm{M})$ & $72(\mathrm{~F})$ \\
& Median $^{*}$ & 24.4 & 15.0 & & \\
\hline
\end{tabular}

*Values stem from individuals who were used twice for the construction of sib pairs but their $\mathrm{Lp}(\mathrm{a})$ levels were used only once for the calculation of the median. ${ }^{*}$ The $\mathrm{Lp}$ (a) levels are significantly higher in the FDB subjects than in their non-FDB sibs as compared by the Wilcoxon matched-pairs signed rank test $(P=0.0033)$.

ference of the $\operatorname{Lp}(\mathrm{a})$ concentration between the members of each pair and calculated the square $\left(\Delta^{2}\right)$. This value was then adjusted for the effect of the size polymorphism. In Caucasians, the relation between the number of K-IV repeats in apo(a) and $\mathrm{Lp}(\mathrm{a})$ concentration is best described by a linear equation (4). Linear regression analysis demonstrated that $55 \%$ of the $\Delta^{2}$ in $\mathrm{Lp}(\mathrm{a})$ levels in the sibs investigated here was explained by the difference of K-IV repeat number between the apo(a) alleles in the two sibs. Therefore adjustment was performed by dividing the $\Delta^{2} \mathrm{Lp}(\mathrm{a})$ by the difference of the number of K-IV repeats present in the apo(a) alleles in the two sibs. The boxplot in Fig. 2 shows these adjusted $\Delta^{2}$ values for the three groups. The variation of the adjusted differences increases with the number of FDB mutations present in the sib pair.

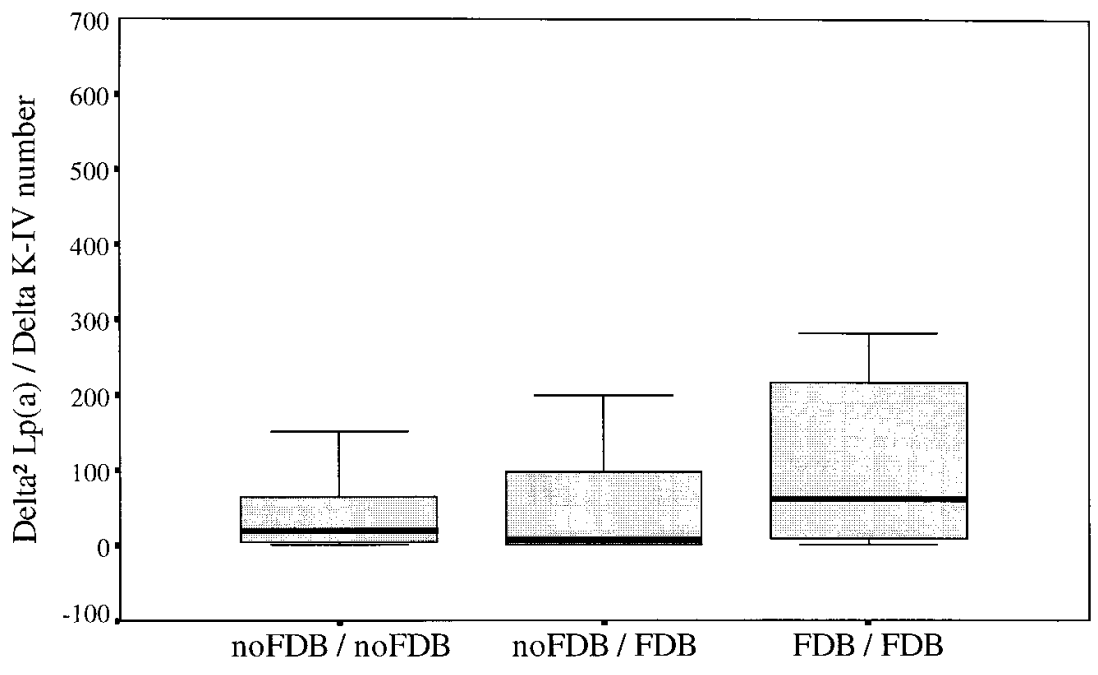

Figure 2. Boxplot of adjusted squared Lp(a) differences within sib pairs which share two $(F D B /$ $F D B)$, one (noFDB / FDB), or no (noFDB / $n o F D B$ ) apoB R3500Q alleles (for further explanation see text). 


\section{Discussion}

The site(s) and mechanism(s) by which $\mathrm{Lp}(\mathrm{a})$ particles are cleared from plasma are still a subject of debate. Lp(a)/apo(a) receptors on macrophages (28), LRP (29), the asialoglycoprotein receptor (7), and the LDL receptor (30) all have been implicated. Because Lp(a) contains apoB-100, one of the principal ligands to the LDL receptor, this receptor became a prime candidate for $\mathrm{Lp}(\mathrm{a})$ clearance from plasma. In vitro and in vivo studies designed to elucidate the role of the LDL receptor, however, have been frustratingly conflicting. Some in vitro studies and $\mathrm{Lp}(\mathrm{a})$ turnover studies in LDL receptor transgenic mice indeed have suggested that the LDL receptor is involved in $\mathrm{Lp}$ (a) clearance $(12-15,28)$, but others do not support this notion $(16,17)$. Indirect evidence from the study of subjects with $\mathrm{FH}$, which is caused by defects in the LDL-receptor gene, is also controversial. Theoretically, individuals expressing only $50 \%$ of functional LDL-receptors on their liver cell membranes, as is the case in heterozygous $\mathrm{FH}$, should have elevated $\mathrm{Lp}(\mathrm{a})$ levels, compared to nonaffected individuals. Several in vivo studies of unrelated $\mathrm{FH}$ patients have found elevated $\mathrm{Lp}$ (a) levels in FH heterozygotes (30-34). In family studies, however, no consistent results were obtained (35-40).

The same is true for FDB. FDB is a relatively recently discovered disorder of lipoprotein metabolism, clinically indistinguishable from $\mathrm{FH}(20)$. It is caused by a $\mathrm{C}$ to $\mathrm{T}$ substitution at nucleotide position 10,699 in exon 26 of the apoB gene which leads to an exchange of Arg for Gln at position 3,500 close to the ligand binding region of apoB-100. This amino acid substitution almost entirely abolishes binding of the apoB-100 protein to the LDL-receptor (19). Consequently, LDL- and total cholesterol levels rise in FDB heterozygotes, and an increased risk for coronary artery disease ensues $(18,19)$. If the LDLreceptor clears Lp(a) from plasma, FDB heterozygotes should also exhibit elevated $\mathrm{Lp}(\mathrm{a})$ levels. Indeed, one study reported elevated Lp(a) levels in FDB heterozygotes compared to nonaffected sibs (41), whereas other authors found no increase of $\mathrm{Lp}(\mathrm{a})$ in FDB subjects $(40,42)$. None of the previous studies has rigorously controlled for the effect of the apo(a) gene on Lp(a) levels, though some have included information from apo(a) phenotyping. Perombelon et al. (41) used apo(a) protein phenotyping to identify apo(a) alleles in their FDB family members. Unfortunately, by this approach it was not possible to establish identity by descent of apo(a) alleles in many cases. However, controlling for a potential confounding effect of the apo(a) locus is mandatory in such studies. Heterogeneity at the hypervariable apo(a) locus almost completely explains the large variation in $\mathrm{Lp}(\mathrm{a})$ levels in the population (2-4). Much of the apo(a) gene effect is explained by a VNTR polymorphism in the apo(a) gene which includes sequences coding for K-IV type 2 domains in apo(a) $(4,43)$. In families, Lp(a) concentrations cosegregate with apo(a) alleles (44). Hence, in family studies, FDB-affected individuals may by chance inherit apo(a) alleles which are associated with $\mathrm{Lp}(\mathrm{a})$ concentrations grossly different from those alleles inherited by their nonaffected family members. As a consequence, $\mathrm{Lp}(\mathrm{a})$ concentrations may be higher, lower, or identical between FDB and non-FDB members depending on the segregation of apo(a) alleles among family members. Here, we have used a sib-pair approach to overcome this problem.

We have selected sib pairs which were identical by descent at the apo(a) locus but nonidentical for FDB status from a large collection of Dutch FDB families. Identity by descent was demonstrated by determination of K-IV repeats in apo(a) by PFGE/genomic blotting in the sibs and their parents. Because of the high heterozygosity $(>95 \%)$ of this polymorphism, it was possible to determine the state of identity for apo(a) alleles for most sibs.

Our approach allowed us to exclude any effect of the apo(a) locus on Lp(a) levels in our analysis. The sibs with the FDB mutation had statistically significantly higher $L p(a)$ levels than those without the mutation. In each single sib pair, Lp(a) concentrations were higher in the FDB-affected than in the nonaffected sib which resulted in a significant difference in $\mathrm{Lp}$ (a) concentrations between the two groups (Wilcoxon matched-pairs signed rank test, $P<0.01$ ).

Notably, no difference in Lp(a) levels was seen between affected and unaffected family members when no stratification for apo(a) alleles was performed. We consider this the first unequivocal demonstration of an effect of the FDB status on $\mathrm{Lp}$ (a) concentration. Our findings, however, do not allow for the conclusion that $\mathrm{Lp}(\mathrm{a})$ is cleared by the LDL-receptor. Though our data support such a scenario, there are other possible interpretations, e.g., the effect of the FDB mutation on $\mathrm{Lp}$ (a) might be an indirect consequence of the disturbed metabolism in FDB subjects rather than reflecting a deficient interaction of Lp(a) particles harboring the apoB R3500Q mutation with the LDL receptor. This is supported by the study of Perombelon et al. (41), who did not find the expected higher percentage of $\mathrm{Lp}(\mathrm{a})$ particles with the apoB R3500Q mutation in the $\mathrm{Lp}(\mathrm{a})$ fraction from FDB patients. This contrasts with the distribution in the LDL fraction from the same patients.

In the 13 FDB families, we identified a total of 105 sib pairs. These were included in a second type of analysis, which was performed to analyze the within-pair variation in $L p(a)$ levels in relation to FDB status. We grouped the sib pairs into three categories according to the presence or absence of the FDB mutation in either both, one, or none of the sibs. Since all sib pairs were from the same families, the same average difference in $\mathrm{Lp}(\mathrm{a})$ concentration within the three groups of sib pairs should be expected if the FDB status had no influence on $\mathrm{Lp}$ (a) levels. We calculated the mean of the squared difference of $\mathrm{Lp}(\mathrm{a})$ concentration within the sib pairs from each group. This parameter is a function of the difference in the number of the K-IV repeats between the members of a pair. To compensate for the effect of differences in the number of K-IV repeats on the $\Delta^{2} \mathrm{Lp}(\mathrm{a})$ value, we divided it by the difference in the number of K-IV repeats between the two sibs. The variation of this adjusted $\Delta^{2}$ value increased with the number of FDB subjects present in the sib pairs. This suggests that FDB not only affects the concentration (level) of $\mathrm{Lp}(\mathrm{a})$, but also the variability of $\mathrm{Lp}(\mathrm{a})$ levels. Therefore, the apoB gene may act as a variability gene (45), not only for plasma apoB levels (46), but also for $\mathrm{Lp}(\mathrm{a})$ concentrations.

\section{Acknowledgments}

We thank A. Freudenstein for her excellent technical assistance.

Dr. J.J.P. Kastelein is a clinical investigator of the Dutch Heart Foundation. This work was supported by grant S07109 from the Fonds zur Förderung der wissenschaftlichen Forschung (Austrian Science Foundation) and by grant PL951678 from the Austrian Ministry for Science, Traffic and Arts to Dr. G. Utermann. 


\section{References}

1. Utermann, G. 1994. Lipoprotein(a). In The Metabolic and Molecular Bases of Inherited Disease. C.R. Scriver, A.L. Beaudet, W.S. Sly, J.B. Stanbury, J.B. Wyngaarden, and D.S. Fredrickson, editors. McGraw-Hill Inc., New York. 1887-1912.

2. Boerwinkle, E., C.C. Leffert, J. Lin, C. Lackner, G. Chiesa, and H.H. Hobbs. 1992. Apolipoprotein(a) gene accounts for greater than $90 \%$ of the variation in plasma lipoprotein(a) concentrations. J. Clin. Invest. 90:52-60.

3. Demeester, C.A., X. Bu, R.J. Gray, A.J. Lusis, and J.I. Rotter. 1995. Genetic variation in lipoprotein (a) levels in families enriched for coronary artery disease is determined almost entirely by the apolipoprotein (a) gene locus. Am. J. Hum. Genet. 56:287-293.

4. Kraft, H.G., S. Köchl, H.J. Menzel, C. Sandholzer, and G. Utermann. 1992. The apolipoprotein(a) gene-a transcribed hypervariable locus controlling plasma lipoprotein(a) concentration. Hum. Genet. 90:220-230.

5. Brewer, H.B., Jr. 1992. Effectiveness of diets and drugs in the treatment of patients with elevated Lp(a) levels. In Lipoprotein(a). A.M. Scanu, editor. Academic Press Inc., Orlando, FL. 211-220.

6. Kostner, G.M., G. Klein, and F. Krempler. 1984. Can serum lipoprotein(a) concentration be lowered by drugs and/or diet? In Treatment of Hyperlipoproteinemia. C.A. Carlson and A.G. Olsen, editors. Raven Press, New York. $151 \mathrm{pp}$.

7. Utermann, G. 1989. The mysteries of lipoprotein(a). Science (Wash. DC). 246:904-910

8. Brunner, C., H.G. Kraft, G. Utermann, and H.J. Müller. 1993. Cysteine 4057 of apolipoprotein(a) is essential for lipoprotein(a) assembly. Proc. Natl. Acad. Sci. USA. 90:11643-11647.

9. Gaubatz, J.W., C. Heideman, A.M.J. Gotto, J.D. Morrisett, and G.H. Dahlen. 1983. Human plasma lipoprotein (a): structural properties. J. Biol. Chem. 258:4582-4589.

10. Koschinsky, M.L., G.P. Cote, B. Gabel, and Y.Y. Van der Hoek. 1993. Identification of the cysteine residue in apolipoprotein(a) that mediates extracellular coupling with apolipoprotein B-100. J. Biol. Chem. 268:19819-19825.

11. McLean, J.W., J.E. Tomlinson, W. Kuang, D.L. Eaton, E.Y. Chen, G.M. Fless, A.M. Scanu, and R.M. Lawn. 1987. cDNA sequence of human apolipoprotein (a) is homologous to plasminogen. Nature (Lond.). 300:132-137.

12. Floren, S., J.J. Albers, and E.L. Bierman. 1981. Uptake of Lp(a) lipoprotein by cultured fibroblasts. Biochem. Biophys. Res. Commun. 10:636-639.

13. Havekes, L., B.J. Vermeer, T. Brugman, and J. Emeis. 1981. Binding of Lp (a) to the low density lipoprotein receptor of human fibroblast. FEBS (Fed. Eur. Biochem. Soc.) Lett. 132:169-173.

14. Hofmann, S.L., D.L. Eaton, M.S. Brown, J.W. McConathy, J.L. Goldstein, and R.E. Hammer. 1990. Overexpression of human low density lipoprotein receptors leads to accelerated catabolism of $\mathrm{Lp}$ (a) lipoprotein in transgenic mice. J. Clin. Invest. 85:1542-1547.

15. Krempler, F., G.M. Kostner, A. Roscher, F. Haslauer, K. Bolzano, and F. Sandhofer. 1982. Studies on the role of specific cell surface receptors in the removal of lipoprotein(a) in man. J. Clin. Invest. 71:1431-1441.

16. Maartman-Moe, K., and K. Berg. 1981. Lp(a) lipoprotein enters cultured fibroblasts independently of the plasma membrane low density lipoprotein receptor. Clin. Genet. 20:352-362.

17. Rader, D.J., W.A. Mann, W. Cain, H.G. Kraft, D. Usher, L.A. Zech, J.M. Hoeg, J. Davignon, M. Grossman, J.M. Wilson, and H.B. Brewer, Jr. 1995. The low density lipoprotein receptor is not required for normal catabolism of Lp(a) in humans. J. Clin. Invest. 95:1403-1408.

18. Hansen, A.T., and S.E. Humphries. 1992. Familial defective apolipoprotein B-100: a single mutation that causes hypercholesterolemia and premature coronary artery disease. Atherosclerosis. 96:91-107.

19. Innerarity, T.L., K.H. Weisgraber, K.S. Arnold, R.W. Mahley, R.M. Krauss, G.L. Vega, and S.M. Grundy. 1987. Familial defective apolipoprotein B-100: low density lipoproteins with abnormal receptor binding. Proc. Natl. Acad. Sci. USA. 84:6919-6923.

20. Defesche, J.C., K.L. Pricker, M.R. Hayden, B.E. Vanderende, and J.J.P. Kastelein. 1993. Familial defective apolipoprotein B-100 is clinically indistinguishable from familial hypercholesterolemia. Arch. Intern. Med. 153:23492356.

21. Defesche, J.C., J.E. Hoogendijk, M. de Visser, O. de Visser, and P.A. Bolhuis. 1990. Genetic linkage of hereditary motor and sensory neuropathy type I (Charcot-Marie-Tooth disease) to markers of chromosomes 1 and 17. Neurology. 40:1450-1453.

22. Demacker, P.N.M., J.B.H.A. Van Oppenraay, H. Baadenhuijsen, and A.P. Jansen. 1975. An improved semi automatic method for the colorimetric determination of triglycerides in serum. Clin. Chim. Acta. 64:45-50.

23. Rochlau, P., E. Bernt, and W. Gruber. 1974. Enzymatische Bestimmung des Gesamtcholesterins im Serum. J. Clin. Biochem. 12:403-407.

24. Demacker, P.N.M., A.G.M. Hijmans, H.E. Vos-Jansen, A. Van't Laarsen, and A.P. Jansen. 1980. A study of the use of polyethylene glycol in estimating cholesterol in high density lipoprotein. Clin. Chem. 26:1775-1779.

25. Friedewald, W.T., R.I. Levy, and D.S. Fredrickson. 1972. Estimation of the concentration of low density lipoprotein cholesterol in plasma, without the use of the preparative ultracentrifugation. Clin. Chem. 18:499-502.

26. Gaubatz, J.W., G.L. Cushing, and J.D. Morrisett. 1986. Quantitation, isolation and characterization of human lipoprotein(a). Methods Enzymol. 129: $167-186$.

27. Kronenberg, F., E. Lobentanz, P. König, G. Utermann, and H. Dieplinger. 1994. Effect of sample storage on the measurement of lipoprotein(a), apolipoproteins B and A-IV, total and high density lipoprotein cholesterol and triglycerides. J. Lipid Res. 35:1318-1328.

28. Snyder, M.L., D. Polacek, A.M. Scanu, and G.M. Fless. 1992. Comparative binding and degradation of lipoprotein(a) and low density lipoprotein by human monocyte-derived macrophages. J. Biol. Chem. 267:339-346.

29. März, W., A. Beckmann, H. Scharnagl, R. Siekmeier, U. Mondorf, I. Held, W. Schneider, K.T. Preissner, L.K. Curtiss, W. Gross, and M. Hüttinger. 1993. Heterogeneous lipoprotein(a) size isoforms differ by their interaction with the low density lipoprotein receptor and the low density lipoprotein receptor-related protein/alpha(2)-macroglobulin receptor. FEBS (Fed. Eur. Biochem. Soc.) Lett. 325:271-275.

30. Utermann, G., F. Hoppichler, H. Dieplinger, M. Seed, G. Thompson, and E. Boerwinkle. 1989. Defects in the LDL receptor gene affect Lp (a) lipoprotein levels: multiplicative interaction of two gene loci associated with premature atherosclerosis. Proc. Natl. Acad. Sci. USA. 86:4171-4174.

31. Bowden, J.F., P.H. Pritchard, J.S. Hill, and J.J. Frohlich. 1994. Lp(a) concentration and apo(a) isoform size. Relation to the presence of coronary artery disease in familial hypercholesterolemia. Arterioscler. Thromb. 14:15611568

32. Mbewu, A.D., D. Bhatnagar, P.N. Durrington, L. Hunt, M. Ishola, S. Arrol, M. Mackness, P. Lockley, and J.P. Miller. 1991. Serum lipoprotein(a) in patients heterozygous for familial hypercholesterolemia, their relatives, and unrelated control populations. Arterioscler. Thromb. 11:940-946.

33. Seed, M., F. Hoppichler, D. Reaveley, S. McCarthy, G.R. Thompson, E. Boerwinkle, and G. Utermann. 1990. Relation of serum lipoprotein(a) concentration and apolipoprotein(a) phenotype to coronary heart disease in patients with familial hypercholesterolemia. N. Engl. J. Med. 322:1494-1499.

34. Wiklund, O., B. Angelin, S.-O. Olofsson, M. Eriksson, G. Fager, L. Berglund, and G. Bondjers. 1990. Apolipoprotein(a) and ischaemic heart disease in familial hypercholesterolaemia. Lancet (N. Am. Ed.). 335:1360-1363.

35. Carmena, R., S. Lussier Cacan, M. Roy, A. Minnich, A. Lingenhel, F. Kronenberg, and J. Davignon. 1996. Lp(a) levels and atherosclerotic vascular disease in a sample of patients with familial hypercholesterolemia sharing the same gene defect. Arterioscler. Thromb. Vasc. Biol. 16:129-136.

36. Defesche, J.C., M.A. van de Ree, J.J. Kastelein, D.E. van Diermen, N.W. Janssens, J.J. van Doormaal, and M.R. Hayden. 1992. Detection of the Pro664-Leu mutation in the low-density lipoprotein receptor and its relation to lipoprotein(a) levels in patients with familial hypercholesterolemia of Dutch ancestry from The Netherlands and Canada. Clin. Genet. 42:273-280.

37. Friedlander, Y., and E. Leitersdorf. 1995. Segregation analysis of plasma lipoprotein(a) levels in pedigrees with molecularly defined familial hypercholesterolemia. Genet. Epidemiol. 12:129-143.

38. Ghiselli, G., A. Gaddi, G. Barozzi, A. Ciarrocchi, and G. Descovich. 1992. Plasma lipoprotein(a) concentration in familial hypercholesterolemic patients without coronary artery disease. Metab. Clin. Exp. 41:833-838.

39. Leitersdorf, E., Y. Friedlander, J.M. Bard, J.C. Fruchart, S. Eisenberg, and Y. Stein. 1991. Diverse effect of ethnicity on plasma lipoprotein(a) levels in heterozygote patients with familial hypercholesterolemia. J. Lipid. Res. 32: 1513-1519.

40. Perombelon, Y.N.F., A.K. Soutar, and B.L. Knight. 1994. Variation in lipoprotein(a) concentration associated with different apolipoprotein(a) alleles. J. Clin. Invest. 93:1481-1492.

41. Perombelon, Y.N.F., J.J. Gallagher, N.B. Myant, A.K. Soutar, and B.L. Knight. 1992. Lipoprotein(a) in subjects with familial defective apolipoprotein B100. Atherosclerosis. 92:203-212.

42. Hansen, P.S., H. Meinertz, H.K. Jensen, P. Fruergaard, J. Launbjerg, I.C. Klausen, L. Lemming, U. Gerdes, N. Gregersen, and O. Faergeman. 1994 Characteristics of 46 heterozygous carriers and 57 unaffected relatives in five Danish families with familial defective apolipoprotein B-100. Arterioscler. Thromb. 14:207-213.

43. Lackner, C., E. Boerwinkle, C.C. Leffert, T. Rahming, and H.H. Hobbs 1991. Molecular basis of apolipoprotein (a) isoform size heterogeneity as revealed by pulsed-field gel electrophoresis. J. Clin. Invest. 87:2153-2161.

44. Utermann, G., H.J. Menzel, H.G. Kraft, C.H. Duba, H.G. Kemmler, and C. Seitz. 1987. Lp(a) glycoprotein phenotype. Inheritance and relation to Lp(a)-lipoprotein concentration in plasma. J. Clin. Invest. 80:458-465.

45. Magnus, P., K. Berg, A.L. Borresen, and W.E. Nance. 1981. Apparent influence of marker genotypes on variation in serum cholesterol in monozygotic twins. Clin. Genet. 19:67-70.

46. Berg, K. 1990. Level genes and variability genes in the etiology of hyperlipidemia and atherosclerosis. In From Phenotype to Gene in Common Disorders. K. Berg, N. Retterstol, and S. Refsum, editors. Munksgaard International Publishers Ltd., Copenhagen. 77-91. 